\title{
GMS syndrome
}

INSERM

\section{Source}

INSERM. (1999). Orphanet: an online rare disease and orphan drug data base. GMS syndrome. ORPHA:2090

GMS syndrome describes an extremely rare syndrome involving goniodysgenesis, intellectual disability and short stature in addition to microcephaly, short nose, small hands and ears, and that has been seen in one family to date. There have been no further descriptions in the literature since 1992. 